\title{
Effectiveness of Demonstration Skill on Use of Nebulization Therapy Among the Parents of Hospitalized Children
}

\author{
Hina Y. Rodge and Archana Maurya \\ Department of Child Health Nursing, SRMM Collage of Nursing, Datta Meghe Institute of Medical Sciences \\ (Deemed to be University), Sawangi Meghe, Wardha, Maharashtra, India
}

\section{ABSTRACT}

Background: For several years, Nebulization therapy has been an effective method in the treatment of respiratory problems. Objectives: 1. To assess the existing demonstration skill on use of Nebulization therapy among the parents of hospitalized children. 2. To assess the effectiveness of demonstration skill on use nebulization therapy among the parents of hospitalized children. 3. To associate the post-test demonstration skill score on use Nebulization therapy among the parents of hospitalized children with selected demographic variables. Material and methods: An interventional research approach with one group pre-test post-test research design was used in this study. 60 samples were selected by Nonprobability conveniently Sampling Technique. A demographic variables and self-Structured Observational Checklist on Nebulization therapy were used to collect the data. Pre-test and demonstration skill was carried on day 1 and post-test conducted with same checklist on 7th day. Results: This study revealed that, Mean value of existing demonstrations skill is 7.41 and post-test demonstrations skill is 16.76 and a standard deviation value of pre-test demonstrations skill is \pm 1.48 and post-test demonstrations skill is \pm 1.48 . The calculated t-value is 15.995 is 'calculated t value' \& 0.00 is 'p value'. Hence it was statistically interpreted that demonstration skill on use of Nebulization therapy among the parents of hospitalized children was effective. Thus, the H1 was accepted and HO was rejected in this study. There was no any association with demographic variables. Conclusion: It is concluded that demonstration skill on use of Nebulization therapy among the parents of hospitalized children was effective.

KEY WORDS: Effectiveness, Demonstration Skill, Nebulization Therapy, Parents, Hospitalized, Children.

\section{INTRODUCTION}

Every child is precious to their parents and family. Today's young children are the future of the nation. If the child is ill, then this results inapprehension, anxiety, helplessness and disturbed lifestyle for the entire family. One among those is respiratory diseases which account for high, mortality among under-five children. The lung is one of the pair of conical organ of the respiratory system, consisting air tubes (bronchi and bronchioles) terminating in air spaces (alveoli). It is unique organ constantly exposure to microorganism and pollutant. It is kept sterile by several defence mechanisms including mucociliary escalator mechanism that plays a noteworthy role to

Biosc Biotech Res Comm P-ISSN: 0974-6455 E-ISSN: 2321-4007

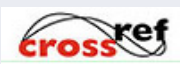

Identifiers and Pagination

Year: 2021 Vol: 14 No (9) Special Issue

Pages: $37-41$

This is an open access article under Creative

Commons License Attribn 4.0 Intl (CC-BY).

DOI: $h t t p: / / d x$.doi.org/10.21786/bbrc/14.9.9 keep the airway sterile. When its function gets affected, it causes respiratory diseases. The respiratory disorder is pathological conditions of respiratory system which involves lungs and other parts of respiratory system.

Acute and chronic childhood respiratory illnesses are one of the first factors for paediatric consultation and can result in substantial health and financial burdens. The upper and lower respiratory tract diseases frequently and simultaneously appears in same patient associate with their pathogenic condition. The upper and lower respiratory tract co-morbidity is also called as United Airway Diseases. Airway conditions can vary from Mild to auto-limiting conditions like Viral Rhinitis to lifeendangering conditions such as Bacterial Pneumonia, Pulmonary Embolism \& Cancer of Lungs. ARI is a respiratory tract infection caused by bacteria and viruses. Out of the two, viruses constitute the greater proportion for the cause of infection. ARIs are more common in young children with seasonal events and also linked to particular respiratory syndromes by certain agents. It may affect the individual's normal breathing and also
Article Information

Received: $12^{\text {th }}$ Apr 2021

ccepted after revision: $12^{\text {th }}$ June 2021 
communicable in nature. More than 12 million children under five years of age admit to hospital every year with ARIs. Worldwide, more than 2 to 6 million deaths caused by lower respiratory tract infections, making them fifth major cause of morality in children under 5 years of age.

Table 1. Percentage wise distribution of samples with selected demographic variables. $\quad n=60$

\begin{tabular}{|c|c|c|}
\hline Demographic Variables & Frequency & $\begin{array}{c}\text { Percentage } \\
(\%)\end{array}$ \\
\hline 20-24 years & 09 & $15 \%$ \\
\hline 25-29 years & 25 & $41.66 \%$ \\
\hline 30-34 years & 23 & $38.34 \%$ \\
\hline 35-39 years & 03 & $5 \%$ \\
\hline \multicolumn{3}{|l|}{ Relationship with child } \\
\hline Mother & 38 & $63.3 \%$ \\
\hline Father & 22 & $36.7 \%$ \\
\hline \multicolumn{3}{|l|}{ Residential area } \\
\hline Urban & 20 & $33.3 \%$ \\
\hline Rural ` & 40 & $66.7 \%$ \\
\hline \multicolumn{3}{|l|}{ Educational status } \\
\hline Illiterate & 0 & $0 \%$ \\
\hline Primary education & 12 & $20 \%$ \\
\hline Secondary education & 05 & $8.3 \%$ \\
\hline Higher Secondary & 22 & $36.7 \%$ \\
\hline Graduate & 21 & $35 \%$ \\
\hline Post graduate and above & 0 & $0 \%$ \\
\hline \multicolumn{3}{|l|}{ Occupation } \\
\hline Laborer & 0 & $0 \%$ \\
\hline Farmer & 6 & $10 \%$ \\
\hline Private employee & 15 & $25 \%$ \\
\hline Government employee & 7 & $11.7 \%$ \\
\hline Self-employed & 2 & $3.3 \%$ \\
\hline Home maker & 30 & $50 \%$ \\
\hline \multicolumn{3}{|l|}{ Monthly Income of family: } \\
\hline Rs. $5000-10,000$. & 12 & $20 \%$ \\
\hline Rs. $10001-15000$. & 25 & $41.7 \%$ \\
\hline Rs.15001-20000. & 14 & $23.3 \%$ \\
\hline above Rs. 20001 & 09 & $15 \%$ \\
\hline \multicolumn{3}{|l|}{ No. of children } \\
\hline 1 & 21 & $35 \%$ \\
\hline 2 & 36 & $60 \%$ \\
\hline 3 & 03 & $5 \%$ \\
\hline More than 3 & 0 & $0 \%$ \\
\hline \multicolumn{3}{|l|}{$\begin{array}{l}\text { Age of the child } \\
\text { (years/months): }\end{array}$} \\
\hline 0-1 year & 25 & $41.7 \%$ \\
\hline 1-2 year & 15 & $25 \%$ \\
\hline 2-3 year & 5 & $8.3 \%$ \\
\hline 3-4 year & 5 & $8.3 \%$ \\
\hline 4-5 year & 10 & $16.7 \%$ \\
\hline
\end{tabular}

The Upper Respiratory Tract Infections like Viral Rhinitis, Pharyngitis \& Otitis Media are more prevalent in children under 5 years of age \&t boys under 3 years of age are more commonly and seriously affected. Aerosol therapy is a technique of administration of medication directly into lungs. The efficacy of the medication is determined by its form, physical and chemical characteristics of the aerosols, aerosol device, breathing pattern of the patient, lung anatomy and physiology. Such local therapies enable smaller doses and minimize systemic adverse effects. The devices that supply aerosols with therapeutic agents use one of different devices: Nebulizers, a Pressurized Meter Dose Inhaler and a Dry-Powder Inhaler. Nebulizer is instrument which converted liquid into aerosol that can be inhaled into the lower respiratory tract. Nebulizer is device that used for aerosol medication administration. It produces a polydisperse aerosol where the drug particles of size range from 1-5 $\mu \mathrm{m}$ in diameter.

Most nebulisers use compressor for atomisation i.e. separate something into fine particles but some use ultrasonic energy. Nebulizers are widely used for Cystic Fibrosis, Asthma, Chronic Obstructive Pulmonary Disease Et other Respiratory problems. Nebulization drug therapy has a very significant part in Paediatric clinical nursing practice. Nurses are primary health care providers that give Nebulization to children by using the nebulizers in a hospital setting. Aerosolized drugs are the clinical cornerstone of several paediatric respiratory paediatric pulmonary disease conditions.Nebulization therapy machine has been used clinically from many years.The use of these equipment is key to an efficient treatment.

Nebulisers prove difficult to use, as they require device assemblies, dosage, dilatants often combined, inhaled for a few minutes and then disassembled, cleaned, sanitized and dried. A nebulizer is used in medicine as a medical device to oversee pharmaceutical products in the form of the inhaled mist in the lungs. Nebulization therapy is commonly used to administer bronchodilators and corticosteroids among the elderly and children. The medicine could be either an antibiotic or medicine for child's lung. As child breaths, the medicine gets inhaled inside to his lungs. When a nebulizer is used, it is referred as breathing treatment or nebulizer treatment.

Several problems may come in assessing Nebulization in children which include age, compliance, problems in drug delivery and drug supplies, anatomical and physiological differences, and trouble able to comprehend when the drug is received by the patient. The medication doses empirically evolved used and new methods of delivery from adult experience have been introduced. Nominal medicine for the infant is also equivalent to that used in older children and adults. The Guidelines of the European Respiratory Society on the use of nebulizers consider the impact of all nebulizer components that may have an effect on the overall performance of the nebulizer including air compressor flow or pressure qualities, attachment tubes, patient interface such as mouthpieces or face masks etc. When one aspect is updated, drug delivery performance and efficiency often change and the nebulizer system needs to be redefined. 


\section{Objectives:}

1. To assess the existing demonstration skill on use of Nebulization therapy among the parents of hospitalized children.

2. To assess the effectiveness of demonstration skill on use Nebulization therapy among the parents of hospitalized children.

3. To associate the post-test demonstration skill score on use Nebulization therapy among the parents of hospitalized children with selected demographic variables.

\section{MATERIAL AND METHODS}

An interventional research approach with one group pretest post-test research design was used in this study. 60 samples were selected by Non- probability conveniently
Sampling Technique. A demographic variables and self-Structured Observational Checklist on Nebulization therapy were used to collect the data. Pre-test and demonstration skill was carried on day 1 and post-test conducted with same checklist on 7th day.

\section{RESULTS}

The percentage wise distribution of samples with selected demographic variables.

The above table no. 1 shows percentage-wise distribution of sample with regards to parents age (in years), relationship with child, residential area, educational status, occupation, monthly income of family, no. of children and age of the child (years/months) regarding effectiveness of demonstration skill on use of Nebulization therapy among the parents of hospitalized children.

\begin{tabular}{|c|c|c|c|c|}
\hline \multirow{2}{*}{ Level of demonstration skill } & \multirow{2}{*}{ Score range } & \multirow{2}{*}{ Percentage score } & \multicolumn{2}{|c|}{ Pre Test } \\
\hline & & & Frequency & Percentage \\
\hline Very Poor & $0-4$ & $0-20 \%$ & 0 & $0 \%$ \\
\hline Poor & $5-8$ & $21-40 \%$ & 45 & $75 \%$ \\
\hline Good & $9-12$ & $41-60 \%$ & 15 & $25 \%$ \\
\hline Very good & $13-16$ & $61-80 \%$ & 0 & $0 \%$ \\
\hline Excellent & $17-20$ & $81-100 \%$ & 0 & $0 \%$ \\
\hline Minimum score & \multicolumn{4}{|c|}{05} \\
\hline Maximum score & \multicolumn{4}{|c|}{12} \\
\hline Mean demonstration skill score & \multicolumn{4}{|c|}{$7.4167 \pm 1.74$} \\
\hline Mean \% demonstration skill score & \multicolumn{4}{|c|}{$37.05 \pm 8.7$} \\
\hline
\end{tabular}

Figure 1: Existing of level demonstration skill on use of Nebulization therapy among the parents of hospitalized children.

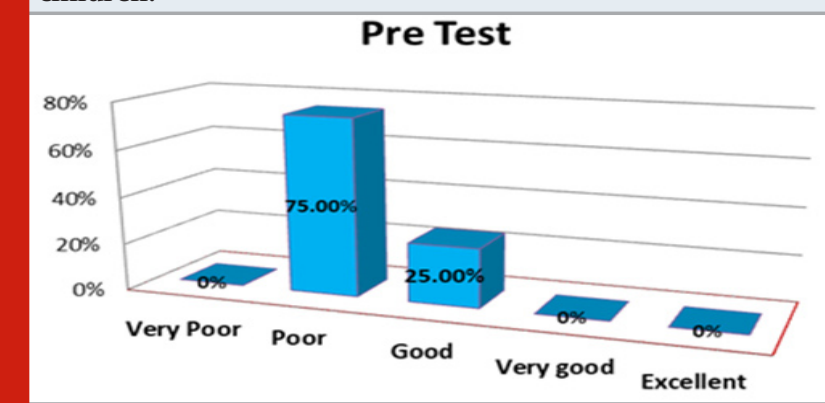

Figure 2: Post-test demonstration skill on use of Nebulization therapy among the parents of hospitalized children.

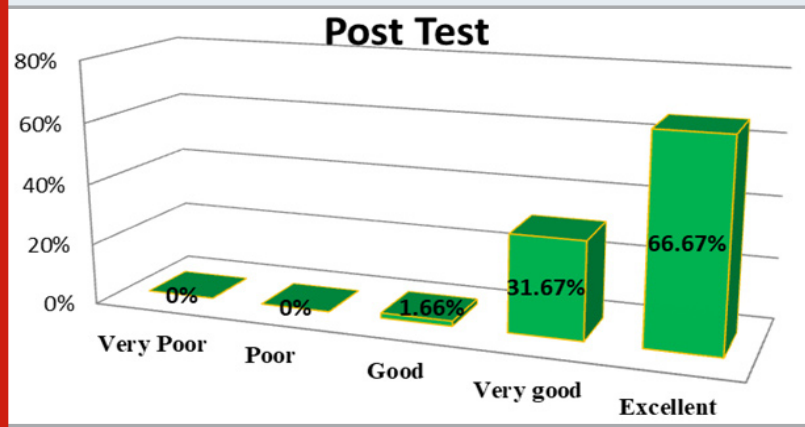

Table 3. Assessment of post-test demonstration skill score on use of Nebulization therapy among the parents of hospitalized children. $n=60$

\begin{tabular}{|c|c|c|c|c|}
\hline \multirow{2}{*}{ Level of demonstration skill } & \multirow{2}{*}{$\begin{array}{c}\text { Score } \\
\text { range }\end{array}$} & \multirow{2}{*}{$\begin{array}{c}\text { Percentage } \\
\text { score }\end{array}$} & \multicolumn{2}{|c|}{ Post Test } \\
\cline { 4 - 5 } & & Frequency & Percentage \\
\hline Very poor & $0-4$ & $0-20 \%$ & 0 & $0 \%$ \\
\hline Poor & $5-8$ & $21-40 \%$ & 0 & $0 \%$ \\
\hline Good & $9-12$ & $41-60 \%$ & 01 & $1.66 \%$ \\
\hline Very good & $13-16$ & $61-80 \%$ & 19 & $31.67 \%$ \\
\hline Excellent & $17-20$ & $81-100 \%$ & 40 & $66.67 \%$ \\
\hline Minimum score & \multicolumn{5}{|c|}{12} \\
\hline Maximum score & \multicolumn{5}{|c|}{$16.76 \pm 1.48$} \\
\hline Mean score skill score & \multicolumn{5}{|c|}{$83.8 \pm 7.4$} \\
\hline $\begin{array}{c}\text { Mean \% demonstration skill } \\
\text { score }\end{array}$ & \multicolumn{5}{|c}{} \\
\hline
\end{tabular}

- Distribution of samples with regards to Parents (Age in Years) shows that 9 (15\%) belong to 21-24 years of age, 25 (41.66\%) belongs to 25-29 years of age, $23(38.34 \%)$ belong to the age of 35-39 years and remaining 3 (5\%) belong to the age of 30-34 years respectively.

- Distribution of samples with regards to their relationship with child shows that 38 (63.3\%) were mother and 22 (36.7\%) were father.

- Distribution of sample with regards to their residential area 20 (33.3\%) were Urban and 40 (66.7\%) were Rural.

- Distribution of samples with regards to their educational status shows $12(20 \%)$ have primary education, 5 (8.3\%) have secondary education, 22 
(36.7\%) have higher secondary and 21 (35\%) are graduate.

- Distribution of sample regards to their occupation $6(10 \%)$ were famer and $15(25 \%)$ were private employee, 7 (11.7\%) were self- employee and 30 (50\%) were home maker.

- Distribution of sample regards to their monthly income of family 12 (20\%) having Rs. 5000-10,000, 25 (41.7\%) having income is Rs. 10001-15,000, 14 (23.3\%) having income is Rs. 15,000-20,000 and 9 (15\%) having income is more than Rs. 20001.

- Distribution of sample regards to their number of children 21 (35\%) parents had single child, 36(60\%) parents had 2 children and 3(5\%) parents had 3 children

- Distribution of sample regards to their age of child in years/months $25(41.7 \%)$ belong to $0-1$ years of age, $15(25 \%)$ belong to $1-2$ years of age, $5(8.3 \%)$ belong to 2-3 years of age, 5(8.3\%) belong to 3-4 years of age and $10(16.7 \%)$ belong to $4-5$ years of age. Assessment of existing demonstration skill score on use of Nebulization therapy among the parents of hospitalized children.
The above table No.2 and Graph No. 1 shows that very poor level of demonstration skill score is $0(0 \%)$, poor level of demonstration skill score is $45(75 \%)$, good level of demonstration skill score is15 (25\%), very good level of demonstration skill score is $0(0 \%)$, excellent level of demonstration skill score is $0(0 \%)$. The minimum score was 05 and the maximum score was 12 , the mean demonstration skill score was $7.4167 \pm 1.74$ with a mean percentage demonstration skill score of $37.05 \pm 8.7$ Assessment of post-test demonstration skill score on use of Nebulization therapy among the parents of hospitalized children.

The above table no. 3 and fig no. 2 shows that of sample were had very poor level of demonstration skill score is $0(0 \%)$, poor level of demonstration skill score is $0(0 \%)$, good level of demonstration skill score is $01(1.66 \%)$, very good level of demonstration skill score is 19 (31.67\%), excellent level of demonstration skill score is 40 (66.67\%).The minimum score was 15 and the maximum score was 18 , the mean score was $16.76 \pm 1.48$ with a mean percentage score of $83.8 \pm 7.4$. The effectiveness of demonstration skill score on use of Nebulization therapy among the parents of hospitalized children.

Table 4. Effectiveness of demonstration skill score on use of Nebulization therapy among the parents of hospitalized children. $n=60$

\begin{tabular}{|l|c|c|c|c|l|}
\hline Tests & Mean score & SD & 't'-value & p-value & Significant \\
\hline Pre Test Demonstration Skill Score & 7.41 & \pm 1.48 & 31.529 & 0.00 & S, $p<0.05$ \\
\hline Post Test Demonstration Skill Score & 16.76 & \pm 1.48 & & & \\
\hline
\end{tabular}

Figure 3: Effectiveness of demonstration skill score on use of Nebulization therapy among the parents of hospitalized children.

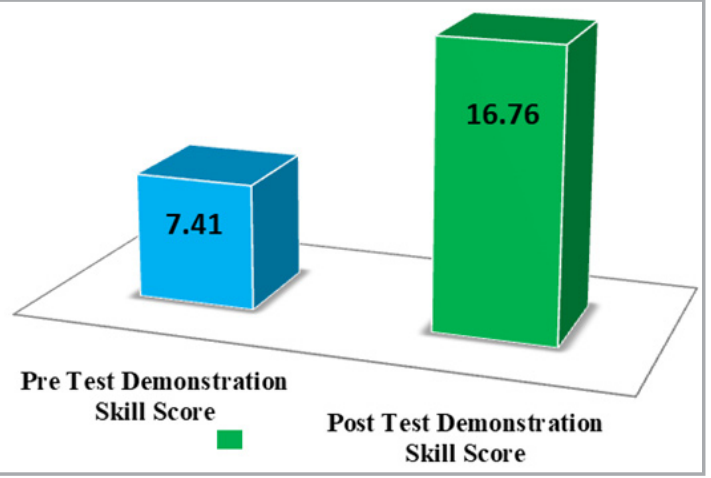

The table No.4 and fig no.3 shows that there is a significant difference between pre-test and post-test demonstration skill scores interpreting effectiveness of demonstration skill on use of Nebulization therapy among the parents of hospitalized children. Mean value of existing demonstrations skill is 7.41 and post-test demonstrations skill is 16.76 and a standard deviation value of existing demonstrations skill is \pm 1.48 and post-test demonstrations skill is \pm 1.48 . The calculated $\mathrm{t}$-value is 15.995 and $\mathrm{p}$-value is 0.00 . Hence it is statistically interpreted that demonstration skill on use of
Nebulization therapy among the parents of hospitalized children was effective. Thus the H1 is accepted and Ho is rejected in this study.

The association of post-test demonstration skill score on use Nebulization therapy among the parents children with selected demographic variables. There is no significance association between demonstration skill score with associated with parents (age in years), relationship with child, residential area, educational status, occupation, monthly income of family, no. of children, age of the child (years/months). Analysis of data showed that there was significant difference between existing and post demonstration skill scores. Hence it is concluded that the demonstration skill significantly brought improvement in the demonstration skill on use of Nebulization therapy among the parents of hospitalized children.

\section{DISCUSSION}

The researcher found that the Mean value of existing demonstrations skill is 7.41 and post-test demonstrations skill is 16.76 and a standard deviation value of pre-test demonstrations skill is \pm 1.48 and post-test demonstrations skill is \pm 1.48 . The calculated t-value is 15.995 and $\mathrm{p}$-value is 0.00 . Hence it is statistically interpreted that demonstration skill on use of Nebulization therapy among the parents of hospitalized children was effective. 
This study is supporting to my study. The study was conducted in hospital at Mangalore on 40 postnatal mothers to assess effectiveness of demonstration on breastfeeding technique. In this study, an interventional approach with a One Group Pre-test Post-test Design' was used. The Purposive Sampling Technique was used to collect samples. This study revealed that after administration of intervention i.e. demonstration on breastfeeding technique the mean post-test practice score was $17.25 \pm 1.444$ which was higher than pre-test practice score $11.3 \pm 2.666$. The calculated t value was 17.59. This finding showed that the postnatal mothers had poor practice on breastfeeding technique \&t after the appropriate intervention [demonstration] the practice on breastfeeding technique had increased. A research concluded that the demonstration program was an effective measure to improve the breastfeeding technique among postnatal mother.

\section{REFERENCES}

Alhaddad B, Taylor KM, Robertson T, Watman G, Smith FJ. (2016) Assistance of family carers for patients with COPD using nebulisers at home: a qualitative study. European Journal of Hospital Pharmacy. May 1;23(3): 156-60.

Barry PW, O'Callaghan C.( 1997) Nebuliser therapy in childhood. Thorax. Apr;52 (Suppl 2): S78.

Beachey W. (2017) Respiratory care anatomy and physiology-e-book: foundations for clinical practice. 4th edition. Elsevier Health Sciences; Mar 22.p.24

Bustamante-Marin XM, Ostrowski LE. (2017) Cilia and mucociliary clearance. Cold Spring Harbor perspectives in biology. Apr 1;9(4):a028241.

Catherine R, Dash MB. (2018) Effectiveness of Salbutamol vs Hypertonic Saline Nebulisation on Breathing Pattern among the Children with Lower Respiratory Tract Infection Admitted to the Selected Hospitals, Puducherry. EC Paediatrics.;7: Pp. 58-63.

Celli BR. (2008) Update on the management of COPD. Chest. Jun 1;133(6): Pp.1451-62.

Force C-C of the T, Boe J, Dennis JH, O'Driscoll BR, Force M of T, Bauer TT, et al.( 2001) European Respiratory Society Guidelines on the use of nebulizers: Guidelines prepared by a European Respiratory Society Task Force on the use of nebulizers. European Respiratory Journal. Jul 1;18(1):228-42.

Fromer L, Cooper CB.( 2008) A review of the GOLD guidelines for the diagnosis and treatment of patients with COPD. International journal of clinical practice. Aug;62(8):Pp.1219-36.
GBD 2013 Mortality and Causes of Death Collaborators. Global, regional, and national age-sex specific all-cause and cause-specific mortality for 240 causes of death, 1990-2013: A systematic analysis for the Global Burden of Disease Study 2013. Lancet 2015; 385: Pp.117-71.

Katiyar SK, Katiyar S.( 2020) Nebulization in the pandemic of coronavirus disease 2019. Indian Journal of Allergy, Asthma and Immunology. Jan 1;34(1):8.

Mrs. Manu Acha Roy, Dr. Theressa Leonida Mendonca, Mr. Mangesh Vilinikaran Jabade.( 2015) Effectiveness of Demonstration On Breastfeeding Technique Among Postnatal Mothers of Newborns In Selected Hospitals, Mangalore. International Journal of Scientific Research. 9 September; 4(9).

NairH, Simões EA, RudanI, Gessner BD, AzzizBaumgartner E, Zhang JS, et al. (2013) Global and regional burden of hospital admissions for severe acute lower respiratory infections in young children in 2010: A systematic analysis. Lancet.;381(9875): 1380-1390.. Park K. (2015) Textbook of Preventive and Social Medicine. ed. 23rd Ch. 5. India: M/s Bhanot Publishers;. Pp.178.

Posa D, Pizzulli A, Wagner P, Perna S, Hofmaier S, Matricardi PM, et al.( 2017) Efficacy and usability of a novel nebulizer targeting both upper and lower airways. Italian Journal of Pediatrics. Sep 29;43 (1):Pp89.

Prajapati S, Saha S, Sahoo B. (2019) Nebulized Drug Delivery: An Overview. Int. J. Pharm. Sci. Res.;10(8): 3575-82.

Savitha A K, Gopalakrishnan S. (2018) Determinants of acute respiratory infections among under five children in a rural area of Tamil Nadu, India. J Family Med Prim Care;7: 1268-73.

Sengupta N, Sahidullah M, Saha G. (2016) Lung sound classification using cepstral-based statistical features. Computers in biology and medicine. Aug 1;75:11829.

Simoes EF, Cherian T, Chow J, Shahid-Salles SA, Laxminarayan R, John TJ. (2006) Acute Respiratory Infections in Children. In: Disease control priorities in developing countries. 2nd edition.; 483-97.

Sims MW. (2011) Aerosol therapy for obstructive lung diseases: device selection and practice management issues. Chest. Sep 1;140(3):781-8.

Tu J, Inthavong K, Ahmadi G. (2012) Computational fluid and particle dynamics in the human respiratory system. Ch. 2.Springer Science \& Business Media; Sep 18. p. 19 